\title{
MEDIASTINAL DUPLICATION OF THE GUT
}

\author{
BY \\ J. STANLEY ELWOOD \\ From the Department of Pathology, The Royal Liverpool Children's Hospital
}

(RECEIVED FOR PUBLICATION APRIL 24, 1959)

Duplication cysts of the mediastinum are not common. Morrison (1958) includes six in a series of 332 mediastinal cysts and tumours; in his Table 1 (which includes his own series) 15 gastric and enterogenous cysts were found in a total of 1,055 published cases of mediastinal cysts and tumours, an incidence of $1.5 \%$.

Although cases have been described (Mixter and Clifford, 1929; Gross, Neuhauser and Longino, 1950; Gross, Holcomb and Farber, 1952; Dickson, Clagett and McDonald, 1946; McLetchie, Purves and Saunders, 1954), it is unusual for duplications of the gut to extend from the abdomen through the diaphragm into the mediastinum.

Details of two cases of mediastinal duplication of the gut occurring in childhood are presented in this communication to illustrate a possible aetiological mechanism.

\section{Case Reports}

Case 1 (R.L.C.H. 14002). This boy attended at the age of 18 months because of pallor and anorexia of recent onset. His left shoulder had drooped since he had started to walk. On physical examination some fullness of the left side of the chest was observed, and dullness and diminished air entry were found posteriorly to the left of the vertebrae. Severe anaemia $(9 \cdot 6 \mathrm{~g}$. \%) was present.

A radiograph of the chest (Fig. 1) revealed (1) a developmental abnormality with hemivertebrae in the mid-dorsal region; scoliosis with concavity to the right, and a slight developmental abnormality of the upper and middle ribs; (2) a rounded opaque shadow situated posteriorly and medially in the upper half of the left side of the chest; and (3) shadowing in the anterior portion of the superior mediastinum (? thymus).

Further radiological examination showed that the oesophagus and whole length of the gut was normal. A small left cervical rib was present and spina bifida of the fifth lumbar and first and second sacral vertebrae was detected. The skull and cervical vertebrae were normal.

A diagnosis of duplication cyst of the gut was made and thoracotomy advised.

At operation a large cystic tumour was found behind the pleura lying on, and closely applied to, the necks of the left ribs, vertebral bodies and the aorta; no localized attachment to the vertebrae was noted. The cyst was removed without difficulty. Convalescence was uneventful and subsequent progress has been satisfactory.

Pathology. The cyst was received fixed in formalin; it measured $3 \times 2 \times 2 \mathrm{~cm}$.; its outer surface was shaggy in places but smooth elsewhere. The interior was pale,

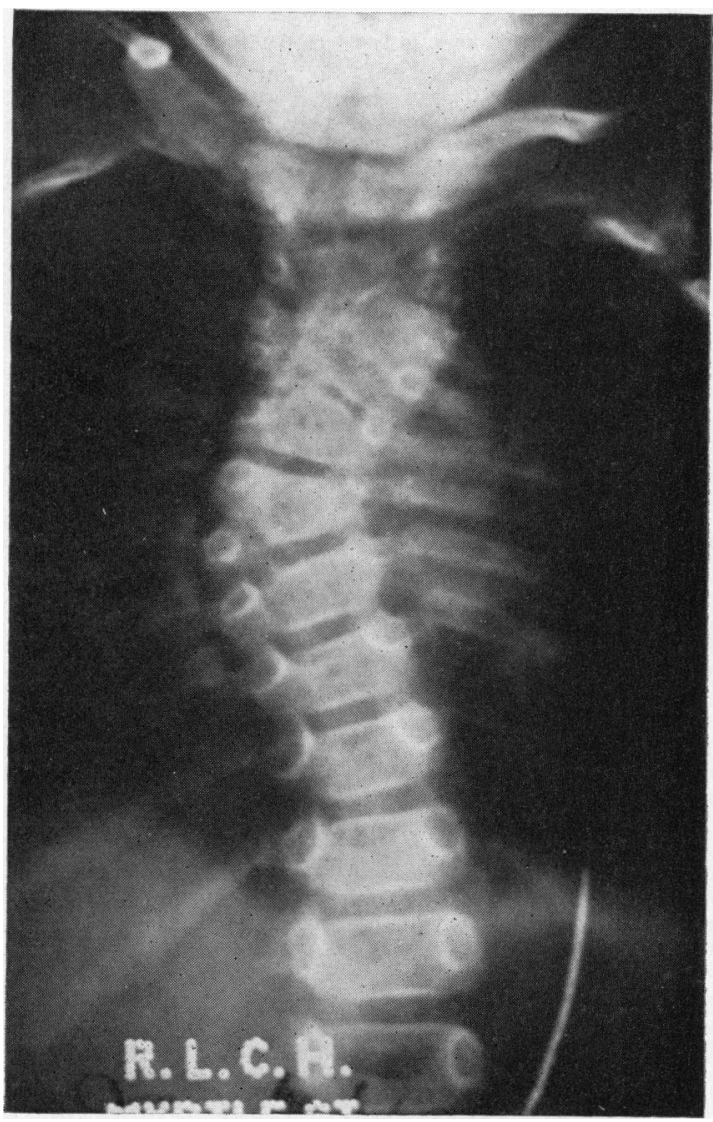

FIG. 1.-Case 1. Radiograph of chest showing abnormal vertebrae with scoliosis and shadowing in upper part of left side of chest. 
smooth and velvet-like over the greater part; in places it was covered by a slough. Microscopic examination of the contents, a reddish-yellow viscous fluid, showed many red cells and some leucocytes but no organisms. The $p H$ was $7 \cdot 6$.

Histological examination (Fig. 2a) showed the wall to be composed of two layers of muscle arranged at rightangles to each other, Auerbach's and Meissner's plexuses being identified. The appearance of the mucosa was variable: over the greater part it was thick, lined by columnar epithelium thrown into short thick villous processes, with racemose glands in its deeper part, sometimes containing oxyntic cells. There was a well developed muscularis mucosae separated from the muscular layers by the submucosa in which were many lymphocytes, sometimes focally aggregated. In one small area the mucosa was reduced to a single layer of columnar cells lying on a thin submucosa and was here devoid of a muscularis mucosae. A single area of ulceration was found in which there was fibrosis of the muscle underlying a slough and fusion of it with the muscularis mucosae as seen in typical peptic ulcers (Fig. 2b).

External to the muscle layers was a thick fibrous layer which showed evidence of haemorrhage and chronic inflammation.

Case 2 (R.L.C.H. 33286). This female infant, weighing $9 \mathrm{lb} .6 \mathrm{oz}$., was born by normal delivery at home. She

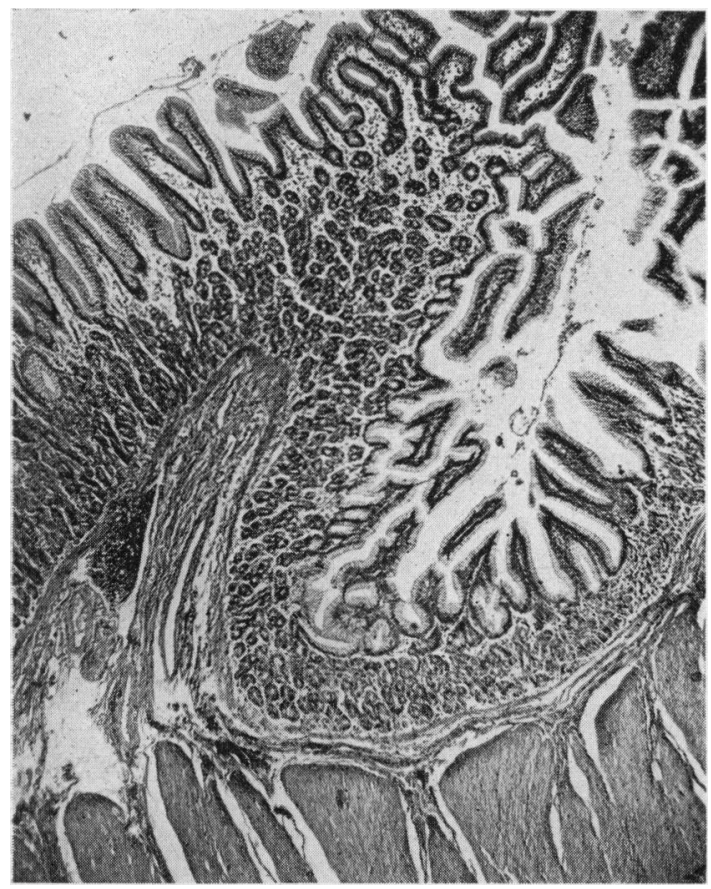

FIG. 2a.-Case 1. Photomicrograph of wall of duplication cyst showing thick mucous membrane containing many oxyntic cells. Note well-developed muscularis mucosae. $(\times 70)$ was the seventh child of healthy parents, the siblings being well. Shortly after birth she was transferred to hospital because of dyspnoea and cyanosis.

A radiograph of the chest (Fig. 3) showed translucency of the right side of the chest with displacement of the heart to the left. Spina bifida of the seventh cervical and upper four dorsal vertebrae was present.

A tentative diagnosis of congenital cystic lung was made and a right thoracotomy was performed 16 hours after birth.

At operation a large mass was discovered deep to the pleura, occupying the postero-inferior portion of the right chest and compressing the right lung, which itself appeared normal. On opening the pleura the mass was seen to be a segment of gut which disappeared from view as it passed through the diaphragm in the right paravertebral fossa. Its upper end thinned out into an elongated process which passed upwards close to and behind the oesophagus to its attachment on the anterior surface of the second dorsal vertebral body, slightly to the left of the midline.

Aspiration of the lesion showed it to contain air and bile. It was freed from its attachments, its upper end being divided between ligatures, but in view of the poor condition of the patient, it was divided and sutured at the diaphragm without exploring its abdominal extension.

Shortly afterwards the child died. Complete radiological examination of the vertebrae after death did not show additional abnormalities.

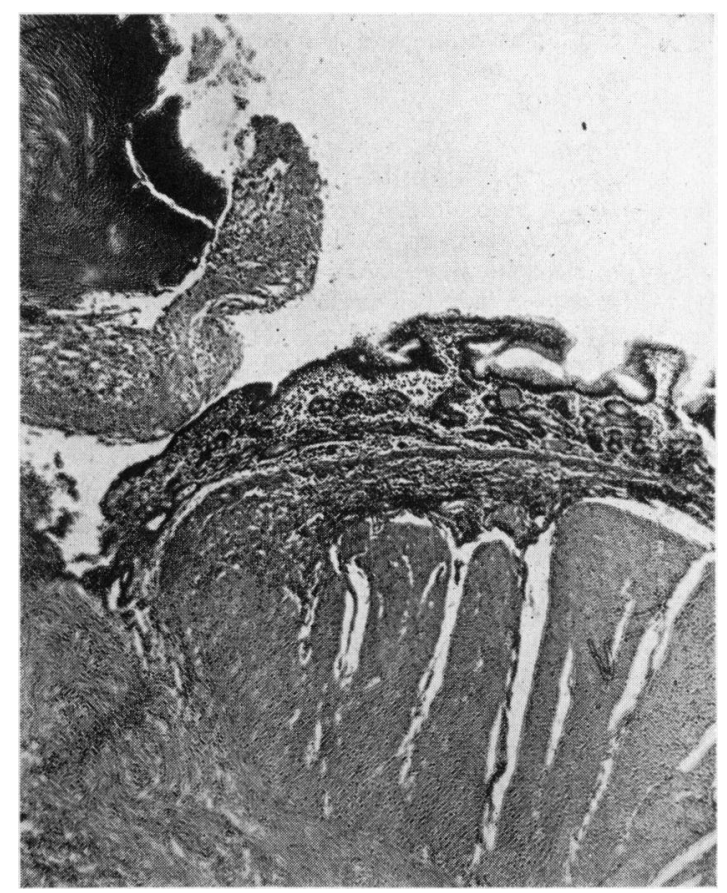

Fig. 2b.-Another area from the same cyst as in Fig. 2a showing ulceration of mucosa which here is devoid of oxyntic cells. $(x 75)$ 


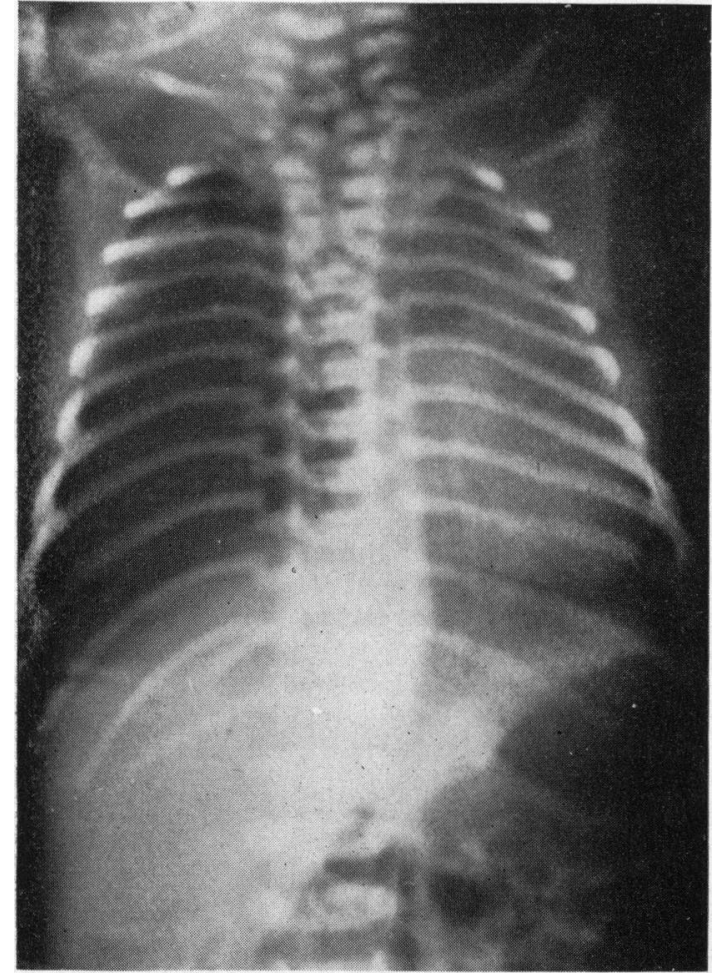

FIG. 3.-Case 2. Radiograph of chest showing translucence on right side and deformity of vertebrae.

Autopsy Findings. The immediate cause of death was haemorrhage into the right thorax, about $50 \mathrm{ml}$. of blood being present.

The oesophagus and stomach were normal in shape and position, the duodenum was normal in its first part but the second part was unduly short and the duodenojejunal flexure was at the ampulla of Vater just to the right of the midline. The ascending colon had a short mesentery which allowed the colon and appendix to lie in the : right hypochondrium. The descending and transverse colon were normal.

Thirty-three centimeters from the pylorus a duplication of the gut arose from its mesenteric border and passed upwards in front of the duodenum and colon to end as a sutured stump under the right cupola of the diaphragm. This duplication was identical in size and appearance to the adjacent jejunum and its stoma admitted a halfcentimeter probe.

The upper ligated stump of the duplication was seen on the anterior aspect of the second thoracic vertebra and, when freed by blunt dissection, passed through this to its attachment on the anterior surface of the spinal cord between the roots of the second thoracic spinal nerves (Fig. 4).

The part of the duplication excised at operation was roughly spherical, $4 \mathrm{~cm}$. in diameter. Externally it was rough, its lower end showing the impress of forceps and its upper end being constricted by a ligature. Its wall was $2 \mathrm{~mm}$. thick and was composed of a thick mucosa lying on muscle.

The hole in the second thoracic vertebra was lined by dura. A coronal section through this part of the vertebral column (Fig. 5) showed the body of T4 to be complete but narrow at its lateral edges; T3 had two wedges of cartilage indenting the sides of its body and T2 was formed by four fragments of bone isolated by cartilage, the hole through which the stump of the diverticulum passed being an elongated vertical median cleft. T1 was likewise formed by four bony fragments. incompletely separated by cartilage. C7 was divided horizontally by a plate of cartilage.

The brain and its membranes were normal; the spinal cord showed a slight localized expansion in the region of the stump of the duplication. The remaining organs were normal.

Histological examination of the duplication (Fig. 6) showed it to be formed of two layers of muscle arranged as in normal gut, Auerbach's and Meissner's plexuses. being present. The submucosa was simple connective tissue without cellular infiltration. The mucosa, limited externally by a muscularis mucosae, was thrown into villous folds with occasional simple gland acini at their bases. The epithelium was a single layer of tall columnar cells with occasional goblet cells. Its appearance was

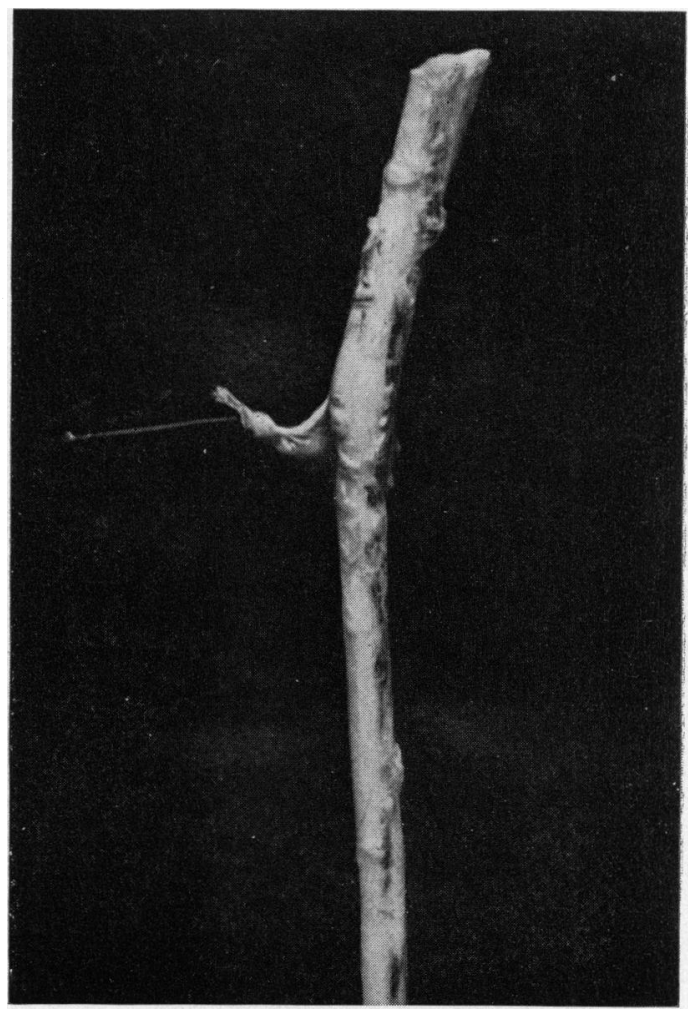

Fig. 4.-Case 2. Stump of duplication of gut attached to spinal cord between anterior roots of second thoracic spinal nerves (lateral view). 


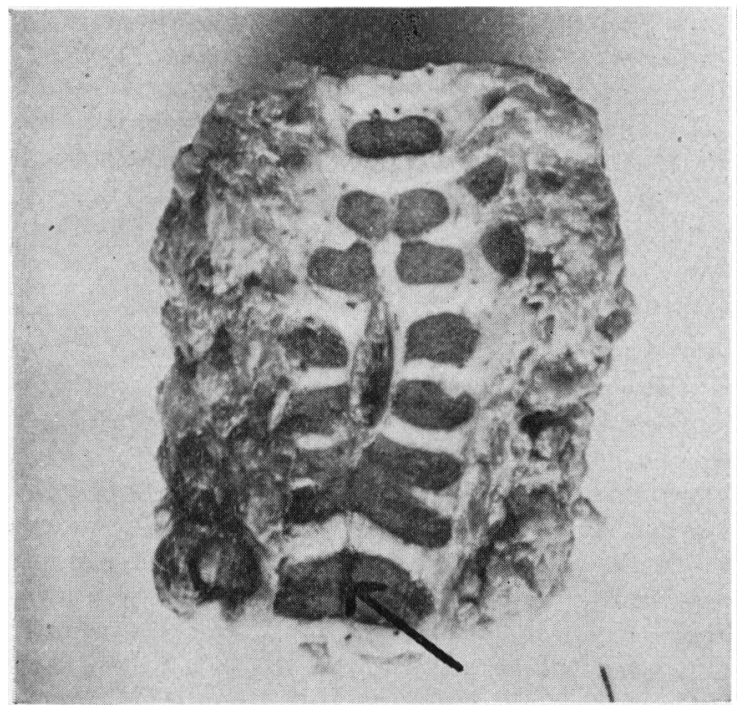

Fig. 5.-Case 2. Coronal section of vertebrae showing cartilage plates dividing the bodies; and median vertical fissure through which the stump of duplication of gut passed to its attachment on spinal cord. Arrow indicates fourth thoracic vertebra.

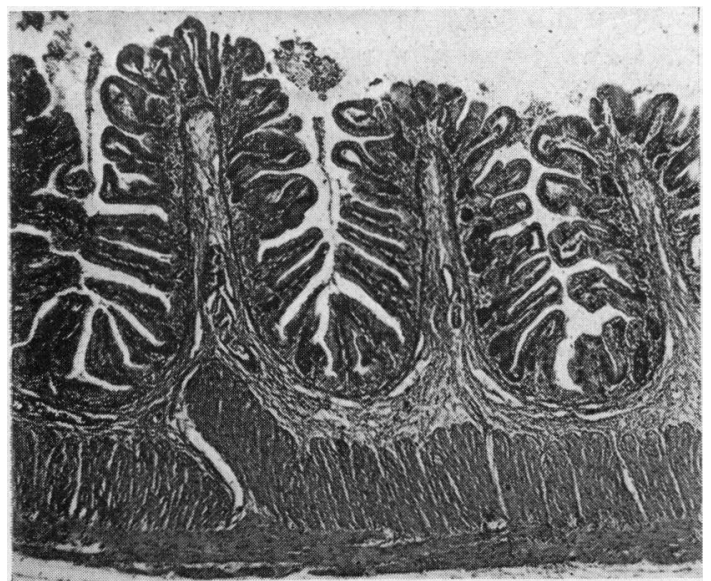

Fig. 6.-Case 2. Section of wall of duplication of gut showing typical appearances of normal jejunum. $(\times 70)$

typical of jejunum, and its structure was constant throughout its length.

The stump, attaching the duplication to the spinal cord, contained a small lumen, lined by squamous epithelium up to four cells thick, which lay ventrally on connective tissue rich in capillaries and sparsely infiltrated with lymphocytes, and containing scattered bundles of smooth muscle (Figs. 7a and b). Dorsally this epitheliallined lumen was covered with a mantle of nervous tissue in which nerve cells, nerve fibres and neuroglia were identified, and was continuous with the white matter of

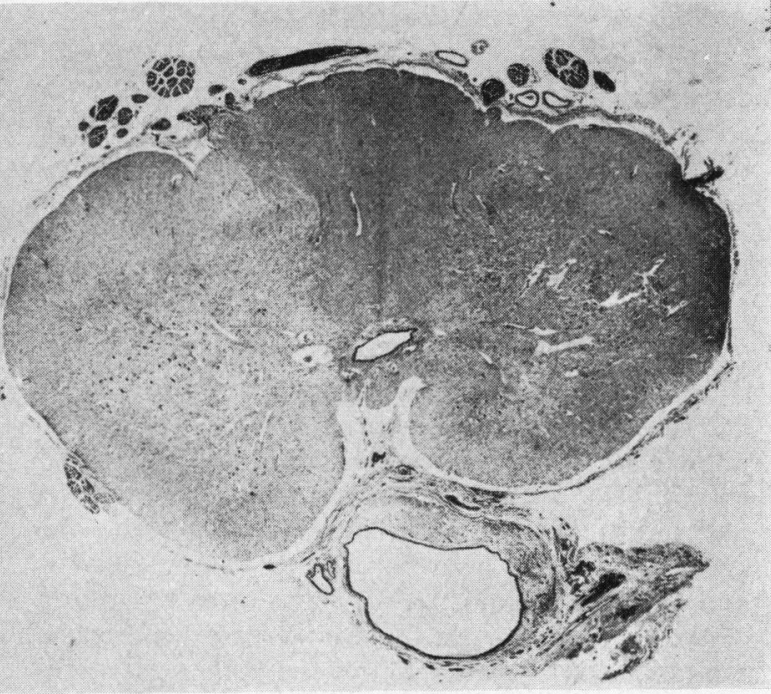

Fig. 7a.-Case 2. Photomicrograph of attachment of duplication of gut to anterior surface of spinal cord. Note mantle of nervous tissue surrounding dorsal aspect of lumen and scattered bundles of smooth muscle in ventral part. $(\times 10$.)

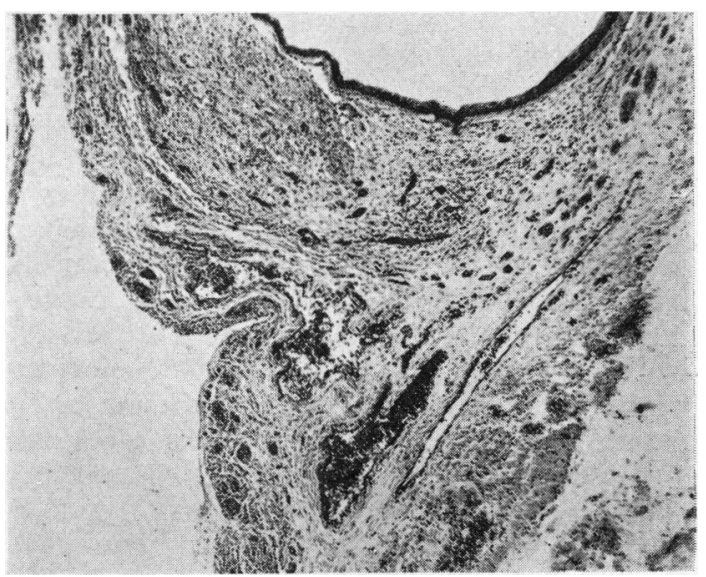

FIG. 7b.-Case 2. Higher power photomicrograph of lumen of diverticulum with mantle of nervous tissue and muscle bundles adjacent to its lumen. $(\times 40$.

the spinal cord. The pia mater of the spinal cord was continuous with a similar covering of the stump.

Serial section of the spinal cord over the extent of the attachment of the duplication failed to show communication between the central canal of the spinal cord and the lumen of the duplication. At the lower end of this attachment the ependyma of the central canal had disappeared and nervous tissue of the duplication projected into its lumen.

The jejunum adjacent to the diverticulum showed a normal microscopic structure. 


\section{Discussion}

The clinical and surgical features of mediastinal duplications of the gut have been discussed by several writers recently and little is to be gained by repetition. Interest centres in the mode of development rather than in the intricacies of diagnosis and treatment of the condition. Five theories which have been advanced to explain its development will be briefly outlined, full accounts being given in the references cited.

I. Incomplete Separation of the Notochord. During the third week of embryonic development the notochord separates from the roof of the entodermal vesicle (yolk sac) and later becomes enveloped by paraxial mesoderm which segments and forms the vertebrae. It has been postulated (Fallon, Gordon and Lendrum, 1954) that in some cases separation of the notochord from the entoderm is incomplete and adhesions between it and the parent entoderm prevent mesodermal envelopment around the notochord, so giving rise to vertebral abnormalities. Medial migration of the mesoderm causes the notochord and entoderm to separate and any adhesion between them would give rise to a traction diverticulum of the entoderm.

II. Ectoderm-entoderm Adhesion. McLetchie et al. (1954) suggest that in the presomite stage a cleft occurs in the notochord, thus permitting the entoderm to become attached to the ectoderm, and in this way a 'neurenteric band' develops which prevents proper medial migration of paraxial mesoderm and so leads to vertebral abnormalities. A traction diverticulum of the entoderm occurs as the entodermal vesicle and ectoderm are separated by medial migration of the paraxial mesoderm. Bremer (1952) postulates that an adhesion between the entoderm and the neural ectoderm gives rise to an 'accessory neurenteric canal' around which the midline structures (notochord, spinal cord and vertebrae) must develop. Vertebral abnormalities of necessity occur and a traction diverticulum of the entoderm develops as the entoderm and ectoderm are ssparated by medial migration of the paraxial mesoderm.

III. Vacuolation Theory. During development of the gut its epithelium proliferates rapidly and the lumen becomes obliterated, never from end to end but only focally (solid stage). Vacuoles filled with secretion from the cells form and later coalesce to reform the lumen, or sometimes, several lumina. With lengthening of the gut its epithelium thins out to cover the increasing surface and vacuoles formed earlier disappear.

Persistence of a vacuole results in a mucosal cyst, and if the epithelium between it and the true lumen breaks down at one point only a mucosal diverticulum results. Development of muscle in its wall is assumed to follow migration of mesoderm into a fissure of the epithelium forming in the neighbourhood of the vacuole; now the wall can become intestinal in structure, not simply mucosal (Evans, 1929; Bremer, 1944; Ladd and Scott, 1944; Gross et al, 1952).

IV. Sequestration of Cells from a Lung Bud. The respiratory tract develops as an out-pouching from the primitive digestive tube, and the lungs form as separate buds on this larger out-pouching. This theory postulates that during the development of the lung bud (or by formation of a similar but separate bud) some cells become sequestrated in the mesoderm and there develop into cystic structures with either enteric, gastric, intestinal or bronchial epithelium (Mixter and Clifford, 1929; Olenik and Tandatnick, 1946; Bickford, 1949; Wooler, 1950).

V. Mucosal Diverticula. Lewis and Thyng (1908) observed diverticula of the mucosa of the intestine, especially in its distal parts, in embryos of pigs, rabbits and in some human embryos. They suggest that these diverticula, although normally disappearing, may occasionally give rise to pathological diverticula.

The majority of authors consider either the vacuolation theory or the theory of sequestration of cells from a lung bud to be the most probable explanation for duplications of the gut occurring in the mediastinum. Only a few favour the mucosal diverticulum theory.

These theories would explain the formation of a duplication closely related to and sharing the muscle coats of the parent gut as has been described in the oesophagus (Ladd and Scott, 1944; Williams and Johnson, 1952). It is unlikely, however, that the muscular wall of a duplication so formed would consist of two layers over the whole of its circumference. But these theories do not offer any explanation for the frequent association of vertebral abnormalities with mediastinal duplications of the gut; this frequent co-existence has been stressed by Veeneklaas (1950) who, visualizing by tomography abnormalities not seen on straight films of the vertebrae, suggests that the association of the two abnormalities is even more frequent than the study of the literature indicates.

Both the theory of incomplete separation of the notochord and the ectoderm-entoderm adhesion theory give a satisfactory explanation of the association of vertebral abnormalities with mediastinal duplications of the gut. If the former theory is 
correct, one would not expect to find any connexion between the duplication and the central nervous system but when such connexion is found the latter theory provides a more satisfactory explanation for the simultaneous development of both abnormalities.

On the basis of the ectoderm-entoderm adhesion theory one would expect to find, in extreme cases, a fistula between the gut and the skin in the midline of the back passing through the vertebrae and spinal cord; such cases have, in fact, been described by Saunders (1943) and Bremer (1952). In less complete examples a tubular extension or solid cord passes from the apex of the duplication to the skin, spinal cord, meninges or vertebrae, traversing midline structures between its attachment and the duplication. Neuhauser, Harris and Berrett (1958) have described three cases of duplication of the gut with vertebral abnormalities and with a solid cord connecting it with the spinal cord; and also one case with a solid process of the duplication attached to the meninges. Budde (1911) recorded a case where a long solid cord, composed of nervous and muscular tissue, traversed abnormal vertebrae to connect the apex of a gastric duplication with the medulla. Case 2 of this communication is a further example of a partly solid cord passing through abnormal vertebrae to connect the spinal cord with the apex of an intestinal duplication.

Although, in some cases, the abdominal connexion of the duplication is retained, all trace of its connexion with midline structures may be lost, as in the cases of Gross et al. (1952); here the vertebral abnormalities are strong presumptive evidence of previous connexion with midline structures.

Finally the abdominal connexion of the duplication may disappear and a single cyst or several cysts may be found at the site of the original duplication. In these cases the dense adhesion of the duplication cyst to the bodies of the vertebrae, themselves frequently abnormal, is a significant fact and is frequently mentioned in case reports.

It must be admitted that no case report of purely abdominal duplication of the gut associated with abnormal vertebrae has been found. If such duplications arise from ectoderm-entoderm adhesions, one must assume that the adhesion has not persisted long enough to prevent envelopment of the notochord by paraxial mesoderm. This is most improbable and such duplications are more reasonably explained by the vacuolation theory or the mucosal diverticulum theory.

In the opinion of the writer, duplications of the gut associated with vertebral abnormalities are most satisfactorily explained by assuming that, early in embryonic development, an adhesion occurring between ectoderm and entoderm produces a traction diverticulum of the entoderm and also prevents proper covering of the notochord by paraxial mesoderm. The final anatomical form of the duplication will be influenced by whether or not its original connexions with the alimentary tract and midline structures are retained and to what extent its lumen remains patent. Its length will be determined to some extent by the site of origin; when arising from entoderm destined to become upper alimentary tract it will lengthen as this descends from the cervical region to its final subdiaphragmatic site. Various epithelial linings are to be expected in the duplication as the primitive fore-gut entoderm can differentiate into squamous, columnar, ciliated or acid-secreting epithelium.

Two cases of mediastinal duplications of the gut are described, one an isolated mediastinal cyst, and the other a jejunal duplication which, passing through the diaphragm into the mediastinum, terminated in a neuromuscular strand attached to the spinal cord. In both cases gross vertebral abnormalities were present.

Several theories explaining the development of this abnormality are briefly reviewed and it is concluded that the most probable assumes that, early in embryonic life, an adhesion, occurring between the ectoderm and entoderm, prevents proper covering of the notochord with paraxial mesoderm and also results in a traction diverticulum of the entoderm.

Due acknowledgment is made to my clinical colleagues, Professor J. D. Hay, Dr. H. G. Farquhar and Dr. Olive Scott, for clinical details of the cases; to Mr. B. J. Bickford, for details of the operative findings; and to Dr. Norah Walker, for reproductions of the radiographs.

The photographs were taken by Miss M. A. Fisher and the photomicrographs by Mr. W. Lee; Mr. Arthur Knowlson prepared many histological sections. To all I record my thanks.

Bickford, B. J. (1949). Brit. J. Surg., 36, 410

Bremer, J. L. (1944). Arch. Path. (Chicago), 38, 132.

(1952). A.M.A. Arch. Path., 54, 132.

Dickson, J. A. Clagett, O. T and McDonald, J. R. (1946). J. thorac Surg., 15, 318 .

Evans, A. (1929). Brit. J. Surg., 17, 34.

Fallon, M., Gordon, A. R. G. and Lendrum, A. C. (1954). Ibid. $41,520$.

Gross, R. E., Neuhauser, E. B. D. and Longino, L. A. (1950). Ann. Surg., 131, 363.

- Holcomb, G. W. and Farber, S. (1952). Pediatrics, 9, 449.

Ladd, W. E. and Scott, H. W. (1944). Surgery, 16, 815.

Lewis, F. T. and Thyng, F. W. (1908). Amer. J. Anat., 7, 505

McLetchie, N. G. B., Purves, J. K. and Saunders, R. L. de C. H. (1954). Surg. Gynec. Obstet., 99, 135.

Mixter, C. G. and Clifford, S. H. (1929). Ann. Surg. 90, 714.

Morrison, I. M. (1958). Thorax, 13, 294.

Neuhauser, E. B. D., Harris, G. B. C. and Berrett, A. (1958). Amer. J. Roentgenol, 79, 235

Olenik, J. L. and Tandatnick, J. W. (1946). Amer. J. Dis. Child.,

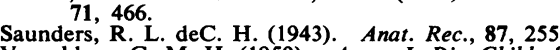

Veeneklaas G. M. H. (1950). Amer. J. Dis. Child., 83, 500

Williams, M. H. and Johnson, J. F. (1952). A.M.A. Arch. Surg., 64, 138.

Wooler, G. H. (1950). Brit. J. Surg., 37, 356. 